\title{
Carcinoma of Unknown Primary Origin: Application of Immunohistochemistry
}

Maral Mokhtari (D maral_mokhtari@yahoo.com )

Shiraz University of Medical Sciences

Dornaz Safavi

Shiraz Medical School: Shiraz University of Medical Sciences

Neda soleimani

Shiraz Medical School: Shiraz University of Medical Sciences

Ahmad Monabati

Shiraz Medical School: Shiraz University of Medical Sciences

Akbar Safaei

Shiraz Medical School: Shiraz University of Medical Sciences

\section{Research}

Keywords: Carcinoma, Carcinoma of unknown primary origin, Immunohistochemistry, cytokeratin, cytokeratin 7, cytokeratin 20

Posted Date: September 7th, 2021

DOI: https://doi.org/10.21203/rs.3.rs-829368/v1

License: () (7) This work is licensed under a Creative Commons Attribution 4.0 International License. Read Full License 


\section{Abstract}

Background: The primary origin of some carcinomas may be obscured to the clinicians but it is crucial to identify the origin of these carcinomas because it affects the prognosis and treatment, especially for the novel targeted therapies. Immunohistochemistry (IHC) may be useful for determination of the primary origins. In this study, we conducted a retrospective survey to evaluate the frequency and accuracy of each IHC marker used to identify the origin of these carcinomas.

Method: Archival review of pathology department revealed 307 cases of carcinoma of known primary origin(CUP) between 2015 and 2020 who were available. Demographic information, site of biopsy, clinical and pathologic diagnosis, and IHC results were collected.

Results: The cases consisted of 157 (51.15\%) male and 150 (48.85\%) female patients. The patients age range was $14-92$ years and 106 cases (34.5\%) were dead. In $27 \%$ of cases, the primary origin remained still unknown. The pathological and clinical diagnostic agreement was $59 \%$. CK7+/CK20- pattern of expression was the most common pattern in CUPs(55.3\%) followed by CK7-/CK20- (19\%), CK7+/CK20+(15\%), CK7-/CK20+(10.7\%), respectively.

Conclusion: IHC study may aid in the diagnosis of CUP. However, some cases will still remain unknown origin after IHC study, so more diagnostic methods or gene expression studies may be needed for definite diagnosis.

\section{Introduction:}

Carcinomas of unknown primary origin (CUP) is a term that is used when a patient is diagnosed with cancer (metastatic), but the primary site cannot be found. It is estimated that the incidence of CUP in all patients diagnosed with cancer is about $4 \%$ (1). CUP commonly manifests as metastasis to lymph nodes, lung, liver, bone, brain, solid organs, and peritoneal and pleural cavities $(2,3)$. About $75-85 \%$ of cases present with disseminated involement $(4)$. It is highly important to identify the origin of the CUP because it affects the prognosis and treatment, especially in novel targeted therapies (1).

Immunohistochemistry (IHC) is the gold standard method in the diagnosis of CUP. In addition, in some settings, gene expression-based tests are used with an accuracy similar to IHC for tumor classification $(>=75 \%)(5,6,7)$. Since the tumor cells are morphologically similar to the tissue they are originated from, they have the same tissue-specific genes in both primary and metastatic cancers (8). We can use limited IHC markers, which is the most appropriate one because usually biopsy specimens of CUP are small and it is difficult to have many cut sections from that tissue(7). Accurate classification of most of the undifferentiated carcinomas as well as careful preservation of tissues for molecular or other ancillary tests could be possible with effective and also systematic use of appropriate IHC panels (9). Generally, two antibody classes are used in CUP work-ups: (A) Antibody to keratin (B) Antibody to organrestricted markers(1).

Although subclassification of carcinomas by high and low molecular weight keratins is useful, it is largely replaced by two more powerful discriminators, which are CK7 and CK20(1). There are four different patterns of expression including CK7+/ CK20+, CK7+/ CK20-, CK7-/ CK20+, and CK7-/ CK20-(9). Although these two important markers are used as the first step for the evaluation of carcinomas, in fact, they have limited capability in the definite diagnosis and should be supported by organ-restricted markers(1). Also these two markers should be interpreted with caution, since there are some overlaps between the patterns $(10,11)$.

Organ-specific makers of carcinomas are subdivided into two classes: (A) Cytoplasmic and/or membranous. Considering the fraction of tumor cells, which are positive for these markers, we can determine the state of differentiation of the tumor. (B) Nuclear transcription factors which are positive in all tumor cells and cannot determine the differentiation of the tumor (1).

In this study, we conducted a retrospective survey to evaluate the frequency and accuracy of each IHC marker used to identify the origin of CUP.

\section{Materials And Methods:}

In this cross-sectional retrospective study conducted from 2015-2020, archives of the pathology and immunohistochemistry department of Shahid Faghihi hospital, affiliated to Shiraz University of Medical Sciences were searched for cases of "carcinoma of unknown primary origin". Our center is one of the main referral centers in the Southwest of Iran. The data of 595 patients were obtained, their H\&E and IHC slides were retrieved, and reviewed. The ethics committee of Shiraz University of Medical Sciences approved the study. 595 cases were found, among them complete data of 307 cases were available. The patients' data were retrieved from their medical records or in cases with missing information the patients or their relatives were contacted. Demographic information, including age, gender, and health status, biopsy site, pathological and final clinical diagnosis were recorded. Frequency of cytokeratin expression and other organ specific immunohistochemical markers for different tumor origin and also the agreement between pathological diagnosis and final clinical diagnosis were analyzed using kappa correlation by SPSS software version 20. P value less than 0.05 was considered as statistically significant. It should be mentioned that final clinical diagnosis was based on pathological results and other work ups such as radiological findings and upper and/or lower gastrointestinal tract endoscopy. None of our deceased patients underwent autopsy.

For pathological diagnosis usual pattern of CK7/CK20 expression and organ specific markers according to published data were used.

All the IHC studies performed using antibodies from Master Diagnostica (Spain), Thermo Fisher Scientific, US and Biocare Medical, US with manual method (Details are summarized in Table 1). Selection of antibodies were based on CK7/CK20 pattern and also patient's age, sex and clinical suspicion, so antibody panels were different in individual cases. 
Table 1

List of Immunohistochemical antibodies used in the study

\begin{tabular}{|c|c|c|c|}
\hline Antibody & clone & Dilution & Company \\
\hline CK7 & $\mathrm{BC} 1$ & Ready to use & Master diagnostic, Spain \\
\hline CK20 & Ks20.8 & Ready to use & Master diagnostic, Spain \\
\hline GATA3 & L50-823 & Ready to use & Master diagnostic, Spain \\
\hline ER & 1D5 & Ready to use & Master diagnostic, Spain \\
\hline GCDFP15 & D6 & Ready to use & Master diagnostic, Spain \\
\hline TTF-1 & $8 G 7 G 3 / 1$ & Ready to use & Master diagnostic, Spain \\
\hline Napsin-A & TMU-Ad 02 & Ready to use & Master diagnostic, Spain \\
\hline P63 & $4 \mathrm{~A} 4$ & Ready to use & Master diagnostic, Spain \\
\hline $\mathrm{CK} 5 / 6$ & CK5/6.007 & Ready to use & Master diagnostic, Spain \\
\hline CK19 & Ks19.1 & Ready to use & Master diagnostic, Spain \\
\hline CD10 & $56 C 6$ & Ready to use & Master diagnostic, Spain \\
\hline vimentin & V9 & Ready to use & Master diagnostic, Spain \\
\hline PAX8 & $\mathrm{BC} 12$ & Ready to use & Master diagnostic, Spain \\
\hline WT-1 & BC.6F-H2 & Ready to use & Master diagnostic, Spain \\
\hline $\mathrm{CDX} 2$ & EP25 & Ready to use & Master diagnostic, Spain \\
\hline SATB2 & EP281 & Ready to use & Biocare Medical, US \\
\hline Villin & CWWB1 & Ready to use & Thermo Fisher Scientific, US \\
\hline Thyroglobulin & $2 \mathrm{H} 11+6 \mathrm{E} 1$ & Ready to use & Master diagnostic, Spain \\
\hline calcitonin & $\mathrm{N} / \mathrm{A}$ & Ready to use & Master diagnostic, Spain \\
\hline P16 & BC42 & Ready to use & Biocare Medical, US \\
\hline Glypican-3 & $1 \mathrm{G} 12$ & Ready to use & Master diagnostic, Spain \\
\hline Arginase & EP261 & Ready to use & Master diagnostic, Spain \\
\hline Hepar-1 & OCH1E5 & Ready to use & Master diagnostic, Spain \\
\hline PSA & EP109 & Ready to use & Master diagnostic, Spain \\
\hline P504 & $13 \mathrm{H} 4$ & Ready to use & Master diagnostic, Spain \\
\hline Cytokeratin HMW & $34 \beta E 12$ & Ready to use & Master diagnostic, Spain \\
\hline
\end{tabular}

\section{Results:}

Among 595 cases of CUP which found during this period, 307 cases were available who enrolled in this study. They consisted of 157 (51.15\%) male and 150 (48.85\%) female patients. The patients' age range was 14-92 years, 220(71.6\%) aged 50 or more than $50 \mathrm{y} / \mathrm{o}$ and $87(28.3 \%)$ were less than $50 \mathrm{y} / \mathrm{o}$. $106 \mathrm{cases}$ (34.5\%) were dead.

The most common site of CUP presentation was the liver. Table 2 shows the frequency of different organs as the first site of tumor presentation. 
Table 2

frequencies of different organs involved by CUP as the first presentation

\begin{tabular}{|llll|}
\hline Site of presentation & Number(\%) & Site of presentation & Number(\%) \\
\hline Liver & $79(25.7)$ & Soft tissue & $3(1)$ \\
\hline Bone & $45(14.6)$ & Skin & $2(0.7)$ \\
\hline Peritoneal cavity & $30(9.8)$ & Uterine cervix & $2(0.7)$ \\
\hline Lung & $23(7.5)$ & Uterus & $2(0.7)$ \\
\hline Bone marrow & $16(5.2)$ & Kidney & $1(0.3)$ \\
\hline Ovary & $14(4.6)$ & Esophagus & $1(0.3)$ \\
\hline CNS & $13(4.2)$ & Lower GI & $1(0.3)$ \\
\hline Neck mass & $11(3.6)$ & Pancreas & $1(0.3)$ \\
\hline Pleural cavity & $8(2.6)$ & Thyroid & $1(0.3)$ \\
\hline Mediastinum & $5(1.6)$ & Prostate & $1(0.3)$ \\
\hline Bladder & $3(1)$ & Total & $307(100)$ \\
\hline
\end{tabular}

In $27 \%$ of cases, the primary origin could not be determined. The frequency of original organs of metastatic cases are mentioned in Fig. 1.

99.4\% of CUP cases were positive for cytokeratin(CK) and only one case had negative CK. CK7/CK20 was checked in 262 cases and we evaluated different patterns of CK7/CK20 expressions in various clinical diagnoses of CUP patients as shown in Fig. 2.

CK7+/CK20-(55.3\%) pattern of expression was the most common pattern in CUPs followed by CK7-/CK20- (19\%), CK7+/CK20+(15\%), CK7-/CK20+(10.7\%), respectively.

\section{1) CK7+/CK20- pattern CUPs:}

In our study, $55.3 \%$ of all CUP cases had CK7+/CK20- pattern of expression, which was the most common pattern in this setting. In this category, unknown origin(24.9\%), lung(22.77\%), breast(17.24\%), pancreatobiliary system(11.72\%), ovary(6.9\%), thyroid(4.13\%), uterus(3.44\%), upper $\mathrm{GI}(2.75 \%)$, lower $\mathrm{GI}(1.37 \%)$, urinary bladder(1.37\%), prostate(1.37\%), liver(0.68\%), kidney(0.68\%), SCC(0.68\%) had the highest frequency, respectively.

\section{2) CK7-/CK20- pattern CUPs:}

This pattern was the second common pattern in our study that is estimated $19 \%$ of our CUP cases. In this category, Prostate(28\%), Unknown origin(26\%), Kidney(14\%), Lung(10\%), Breast(8\%), Upper GI(4\%), Liver(4\%), Nasopharynx and SCC(6\%) had the highest frequency, respectively.

\section{3) $\mathrm{CK} 7+/$ CK20 + pattern CUPs:}

This pattern was found as the third common pattern that accounted for $15 \%$ of our cases. In this category, Unknown origin (38.5\%), Pancreatobiliary system (23.07\%), Upper GI(10.25\%), Lower GI(7.69\%), urinary bladder(10.25\%), Lung(5.12\%), Ovary(5.12\%) had the highest frequency, respectively.

\section{4) CK7-/CK20 + pattern CUPs:}

This was the least common category, which included $10.7 \%$ of our cases. In this category, Lower $\mathrm{Gl}(60.73 \%)$, Unknown origin(21.42\%), Appendix(7.14\%), Upper GI(7.14\%), Urinary Bladder(3.57\%) had the highest frequency, respectively.

Table 3 shows the frequency of Organ-specific IHC markers in different clinical diagnosis. 
Table 3

The frequency of IHC markers in different clinical diagnosis. *: total number of case which were checked for the marke

\begin{tabular}{|c|c|c|c|c|c|c|c|c|c|c|c|c|c|c|c|c|c|c|c|c|c|}
\hline \multirow{2}{*}{\multicolumn{2}{|c|}{$\begin{array}{l}\text { Breast } \\
\text { Total:32 }\end{array}$}} & \multicolumn{2}{|c|}{ Kidney } & \multicolumn{2}{|c|}{ Cervix } & \multicolumn{2}{|c|}{ Ovary } & \multicolumn{2}{|c|}{ Uterus } & \multicolumn{2}{|c|}{ Lung } & \multicolumn{2}{|c|}{ Bladder } & \multicolumn{2}{|c|}{ Prostate } & \multicolumn{2}{|c|}{ Lower GI } & \multicolumn{2}{|c|}{ Upper GI } & \multicolumn{2}{|c|}{ Liver } \\
\hline & & \multicolumn{2}{|c|}{ Total:10 } & \multicolumn{2}{|c|}{ Total:3 } & \multicolumn{2}{|c|}{ Total:17 } & \multicolumn{2}{|c|}{ Total:6 } & \multicolumn{2}{|c|}{ Total:44 } & \multicolumn{2}{|c|}{ Total:7 } & \multicolumn{2}{|c|}{ Total:19 } & \multicolumn{2}{|c|}{ Total:23 } & \multicolumn{2}{|c|}{ Total:15 } & \multicolumn{2}{|c|}{ Total:4 } \\
\hline \multicolumn{2}{|l|}{ ER } & \multicolumn{2}{|c|}{ CD10 } & \multicolumn{2}{|c|}{ P16 } & \multicolumn{2}{|c|}{ WT1 } & \multicolumn{2}{|c|}{ PAX8 } & \multicolumn{2}{|c|}{ TTF1 } & GAT & & PSA & & CDX & & CDX & & Hep & ar1 \\
\hline *No & $\begin{array}{l}+ \\
(\%)\end{array}$ & No & $+(\%)$ & No & $\begin{array}{l}+ \\
(\%)\end{array}$ & No & $\begin{array}{l}+ \\
(\%)\end{array}$ & No & $\begin{array}{l}+ \\
(\%)\end{array}$ & No & $\begin{array}{l}+ \\
(\%)\end{array}$ & No & $+(\%)$ & No & $\begin{array}{l}+ \\
(\%)\end{array}$ & No & $\begin{array}{l}+ \\
(\%)\end{array}$ & No & $\begin{array}{l}+ \\
(\%)\end{array}$ & No & $\begin{array}{l}+ \\
(\%)\end{array}$ \\
\hline 26 & 73.1 & 26 & 73.1 & 2 & 100 & 11 & 72.2 & 4 & 100 & 41 & 73.2 & 6 & 50 & 4 & 50 & 22 & 95.5 & 14 & 50 & 2 & 0 \\
\hline GATA & & Vim & ntin & P63 & & PAX & & ER & & Nap & & P63 & & P50 & & Villir & & Villir & & Argi & lase \\
\hline No & $\begin{array}{l}+ \\
(\%)\end{array}$ & No & $+(\%)$ & No & $\begin{array}{l}+ \\
(\%)\end{array}$ & No & $\begin{array}{l}+ \\
(\%)\end{array}$ & No & $\begin{array}{l}+ \\
(\%)\end{array}$ & No & $\begin{array}{l}+ \\
(\%)\end{array}$ & No & $+(\%)$ & No & $\begin{array}{l}+ \\
(\%)\end{array}$ & No & $\begin{array}{l}+ \\
(\%)\end{array}$ & No & $\begin{array}{l}+ \\
(\%)\end{array}$ & No & $\begin{array}{l}+ \\
(\%)\end{array}$ \\
\hline 27 & 88.9 & 27 & 88.9 & 3 & 33.3 & 13 & 76.9 & 6 & 50 & 21 & 76.2 & 5 & 80 & 18 & 83.3 & 3 & 100 & 1 & 100 & 1 & 0 \\
\hline GCD & P15 & PAX & & CK5 & & ER & & ER\& & & PAX & & $\mathrm{HM}$ & & PSA & & SAT & & SAT & & Hep & ar1\& \\
\hline & & & & & & & & PAX & & & & & & P50 & & & & & & Argi & lase \\
\hline No & $\begin{array}{l}+ \\
(\%)\end{array}$ & No & $+(\%)$ & No & $\begin{array}{l}+ \\
(\%)\end{array}$ & No & $\begin{array}{l}+ \\
(\%)\end{array}$ & No & $\begin{array}{l}+ \\
(\%)\end{array}$ & No & $\begin{array}{l}+ \\
(\%)\end{array}$ & No & $+(\%)$ & No & $\begin{array}{l}+ \\
(\%)\end{array}$ & No & $\begin{array}{l}+ \\
(\%)\end{array}$ & No & $\begin{array}{l}+ \\
(\%)\end{array}$ & No & $\begin{array}{l}+ \\
(\%)\end{array}$ \\
\hline 7 & 57.1 & 7 & 57.1 & 3 & 66.7 & 11 & 54.5 & 4 & 50 & 16 & 0 & 2 & 50 & 4 & 50 & 2 & 100 & 1 & 0 & 1 & 0 \\
\hline ER\& & & $\mathrm{RCC}$ & & P16 & & WT & & & & TTF & & GAT & 3\&p63 & & & CDX & & & & & \\
\hline GATA & & & & P63 & & PAX & & & & Nap & & & & & & SAT & & & & & \\
\hline No & $\begin{array}{l}+ \\
(\%)\end{array}$ & No & $+(\%)$ & No & $\begin{array}{l}+ \\
(\%)\end{array}$ & No & $\begin{array}{l}+ \\
(\%)\end{array}$ & & & No & $\begin{array}{l}+ \\
(\%)\end{array}$ & No & $+(\%)$ & & & No & $\begin{array}{l}+ \\
(\%)\end{array}$ & & & & \\
\hline 21 & 69.9 & 21 & 69.9 & 2 & 50 & 8 & 62.5 & & & 21 & 71.4 & 4 & 50 & & & 2 & 100 & & & & \\
\hline & & $\mathrm{CD}^{-}$ & & P16 & & WT & & & & & & & & & & CDX & & & & & \\
\hline & & Vim & tin & CK5 & & ER & & & & & & & & & & Villir & & & & & \\
\hline & & No & $+(\%)$ & No & $\begin{array}{l}+ \\
(\%)\end{array}$ & No & $\begin{array}{l}+ \\
(\%)\end{array}$ & & & & & & & & & No & $\begin{array}{l}+ \\
(\%)\end{array}$ & & & & \\
\hline & & 5 & 80 & 2 & 100 & 9 & 66.7 & & & & & & & & & 3 & 100 & & & & \\
\hline & & $\mathrm{CD}^{-}$ & \&PAX8 & & & & & & & & & & & & & & & & & & \\
\hline & & No & $+(\%)$ & & & & & & & & & & & & & & & & & & \\
\hline & & 6 & 66.7 & & & & & & & & & & & & & & & & & & \\
\hline
\end{tabular}

In this study, the pathological and clinical diagnostic agreement was $59 \%$.

\section{Discussion:}

This retrospective study included all cases of CUP at Shahid Faghihi hospital from 2015 to 2020 which were available. Among total 307 cases, the final diagnosis for primary origin for $27(8.7 \%)$ cases remained unknown despite surveys and ancillary and diagnostic modalities. In a previous study by Brown et al., metastatic tumors were evaluated and the origin of $14 \%$ of cases remained indeterminate (12).

\section{Gastrointestinal(GI) tract origin:}

In this study, all patterns of CK7/CK20 expression were seen in GI origin cases with the CK7+/CK20- patients were the most prevalent pattern in Upper GI and CK7-/CK20 + in lower GI origins, respectively.

CDX2 was positive in $95.5 \%$ of cases of lower $\mathrm{GI}$ and $50 \%$ of upper $\mathrm{Gl}$ origin carcinomas. Previous studies showed that CDX2 could be positive in more than $90 \%$ of colorectal cancer $(1,13,14,15,16)$. However, Su et al. and Bayrak et al. showed that CDX2 is not a good predictor of the lower $\mathrm{Gl}$ origin because it could be positive in all GI tract origin cases $(17,18)$. CDX2 positivity in in different studies ranged from $18 \%$ to more than $70 \%$ in gastric cancers $(17,15,22$, 24) and Vang et al. showed CDX2 expression in $74 \%$ of metastatic gastric cancers to the ovary (25). Special AT-rich sequence-binding protein 2(SATB2) was positive in our lower GI cases. This marker also showed high sensitivity and specificity for colorectal origin $(1,14,16)$ and Ma et al. demonstrated SATB2 as a novel marker with $85 \%$ expression in both primary and metastatic signet ring colorectal origins (19). But it is not a good marker for diagnosis of upper GI origin $(13,19,26)$. Villin was positive in our upper and lower GI origin malignancies, Previous studies showed a high positive rate range from $75 \%$ to more than $90 \%$ 
in colorectal carcinomas (especially in well differentiated cases) but lower rates in upper GI tumors $(1,14,20,21,22)$. Although it is noteworthy to mention that villin expression is not limited to GI malignancies. Werling et al. study stated that Villin was positive in $40 \%$ of pancreatic carcinomas, $78 \%$ of esophageal carcinomas, and $64 \%$ of mucinous ovarian adenocarcinomas(21).

It seems that using CDX2, Villin, and SATB2 is helpful for determining the lower GI origin. And combination of Villin and CDX2 in cases with suspicious upper Gl origin will increase diagnostic yield.

\section{Liver:}

We had 4 cases with clinical diagnosis of liver as the primary source without accurate pathologic diagnosis. They were $66.7 \%$ CK7-/CK20- and 33.3\% CK7+/CK20-.

Hepatocyte Paraffin 1(Hep Par1) and Arginase were checked and were negative.

In Kandalaft et al. study, Hep Par1 was positive in $70-100 \%$ of cases (1). Also, another experiment by Yan et al. showed $96 \%$ sensitivity for arginase 1 even for poorly differentiated hepatocellular carcinomas(27). Radwan et al. showed arginase 1 and Hep Par1 expression of $84 \%$ and $70 \%$, respectively, and they believed that in high-grade tumors, sensitivity and specificity of arginase1 were more than heppar1 (28). Also, a similar study by Koehne de Gonzales et al. estimated the sensitivity and specificity of Hep Par1 as $70 \%$ and $84 \%$, and for arginase $184 \%$ and $96 \%$, respectively (29). No hepatic-specific markers were expressed in our cases and they may be better to be considered as undetermined origin.

\section{Breast:}

In our study. CK7+/CK20- pattern was seen in $86.2 \%$ and CK7-/CK20- pattern in $13.8 \%$ of breast origin cases.

Estrogen receptor(ER), was in 73.1\%, GATA3 was in $88.9 \%$ and Gross cystic disease fluid protein 15(GCDFP15) was positive in $57.1 \%$ breast origin malignancies. Previous studies stated that GATA3 has more sensitivity for diagnosis of breast cancer compared to GCDFP15 (1, 30, 31, 32, 33, 34, 35, 36). The positive rate for GCDFP15 is still lower in metastatic cases (33)

In O' Connell et al. research, ER and GCDFP15 expression in metastatic breast cancer was calculated to be $72 \%$ and $78 \%$, respectively (30). Kandalaft et al. study recommended GCDFP-15, GATA3, and mammaglobin panel (1), but in our study it seem that combination of ER and GATA3 can be helpful in diagnosis of breast origin in a high proportion of our cases.

\section{Kidney:}

In this study, the most prevalent CK7/CK20 pattern in kidney origin cases were CK7-/CK20- followed by CK7+/CK20- pattern.

For determining kidney origin we used CD10, vimentin and PAX8 panel which showed positivity in more than $70 \%$ of renal malignancies.

In previous studies by PAX8 had more than $70 \%$ positivity in kidney carcinomas $(37,38)$. and the intensity of its expression is higher in the metastatic cases (39). Tong et al. (40) and Tacha et al. (37) showed that PAX8 is a specific marker for both primary and metastatic RCC. Liu et al. stated that CD10 is positive in $91 \%$ of clear cell RCC and vimentin is $100 \%$ sensitive for clear cell RCCs (41). Sharma et al. believed that PAX 8 and RCC markers are $100 \%$ sensitive in metastasis with kidney origin (42). In our study combination of vimentin, PAX8, and CD10 was successful to identify kidney origin in acceptable number of patients.

\section{Uterine cervix:}

CK7+/CK20- was the most prevalent pattern seen in our uterine cervix origin cases. All cases were poorly differentiated; thus, types of cervical cancers (SCC and adenocarcinoma) could not be determined on histomorphology. Combination of P16, P63 and CK5/6 were used in our study. It has been stated that these markers have good sensitivity and specificity for diagnosis of $\operatorname{SCC}(43,44,45,46,47,48)$.

Wang et al. showed strong P16 expression in 98\% of metastatic cervix SCC to lung (49).

\section{Ovary:}

In our study, $83.3 \%$ of ovarian origin cancers were CK7+/CK20- and $16.7 \%$ were $\mathrm{CK} 7+/ \mathrm{CK} 20+$.

In CK7+/CK 20 pattern carcinomas, Wilms tumor (WT)1 was positive in 72.7\%, PAX8 was positive in 76.9\% and ER was positive in $54.5 \%$ However one study by Tacha et al. revealed more than $90 \%$ positivity for WT1 and another study showed $70-99 \%$ for PAX8(37, 38). Also Ordo'nez et al showed ER expression in $85-90 \%$ of ovarian cancers (50).

WT1 and PAX8 combination were positive in about $66.7 \%$ of our patients. Since serous carcinoma of the ovary is the most common ovarian epithelial neoplasm with a high risk of dissemination we can use WT1 and PAX8 and ER as a good panel with high sensitivity for diagnosis of ovarian origin carcinoma especially in CK7+/CK20- pattern. In CK7+/CK20 + pattern mucinous carcinoma should be considered so other IHC markers such as CDX2 will be helpful.

\section{Uterus:}

All of uterine origin cases were CK7+/CK20-. PAX8 and ER marker was positive in $100 \%$ and $50 \%$ of cases, respectively.

PAX8 expression according to Tacha and Ozcan et al. was seen in 84-93\% of endometrial carcinomas (37, 38)., and in Yemelyanova et al. study, PAX8 was reported as a useful marker to determine uterine origin of adenocarcinomas in extrauterine sites (51). Thus, all previous studies are concordant with our study 
for the PAX8 marker. In addition in Alkushi et al. study and the Kounelis survey, ER expression were seen in $73 \%$ and $54 \%$ of endometrial carcinomas, respectively $(52,53)$.

\section{Lung:}

In this study, 82.5\% lung origin tumors were CK7+/CK20-, 12.5\% CK7-/CK20-, and 5\% were CK7+/CK20+.

Thyroid transcription factor (TTF) 1 was positive in $73.2 \%$. Which is in concordant to previous studies. The positivity of TTF has been reported from $70-100 \%$ in various lung malignancies $(9,45,54-59)$. And lower frequency in poorly differentiated adenocarcinomas (9).

In our study, Napsin A was positive in $76.2 \%$ According to other studies, Napsin A is positive in more than $80 \%$ of patients (60,59). It has been stated that this marker is more sensitive than TTF1 in the diagnosis of lung carcinoma (57). In our study, PAX8 was negative in lung origin carcinomas which is helpful to differentiate these tumors from thyroid origin tumors which both are TTF-1 positive. Ye et al., also stated that PAX8 was negative in their lung adenocarcinomas (59).

We recommend using both TTF1 and Napsin A as a panel with acceptable sensitivity to detect lung adenocarcinoma.

\section{Thyroid:}

Thyroid origin were CK7+/CK20-.

\section{Follicular cell origin thyroid carcinoma:}

Among 6 follicular cell origin cases, $83.3 \%$ were positive for TTF1. Thyroglobulin (TG) and PAX8 were positive in $100 \%$ of cases.

\section{C cell type origin thyroid carcinoma:}

Both medullary carcinomas cases found to co-express TTF1 and calcitonin and TG was negative.

Our study was concordant with previous studies, i.e. high sensitivity for TTF-1 and PAX8 was documented in thyroid origin cases. The positivity was more frequent in well differentiated thyroid follicular origin tumors (papillary carcinoma and follicular carcinoams) compared to medullary thyroid carcinomas and anaplastic carcinomas $(11,61-66)$.

However, Zhang et al. results is not consistent with other studies and showed PAX8 positivity in $31.2 \%$ of PTC and $40 \%$ of FTC cases (67).

TG expression showed variable results in thyroid follicular epithelial malignancies and in metastatic sites range from $60-100 \%$ in different studies (61, 62 , 68).

So it seems that combination of TTF1, TG, and PAX8 as a panel of markers with $100 \%$ sensitivity for follicular cell origin cases. Positive TTF1 and calcitonin with negative $T G$ are also a good predictor for $\mathrm{C}$ cell origin.

\section{Prostate:}

In our Prostate origin tumors $87.5 \%$ were CK7-/CK20- and 12.5\% were CK7-/CK20+.

P504 and prostate specific antigen (PSA) were positive in $83.3 \%$ and $50 \%$ cases respectively.

Co expression of PSA and P504 were seen in 50\% of patients. In previous studies PSA expression showed a high sensitivity and specificity for diagnosis of prostate carcinoma (69-70) but its utility will be less in metastatic sites (71).

According to Mai and Renshaw et al. studies, the possibility of PSA expression is higher in well-differentiated prostatic cancers in comparison with high-grade types $(72,73)$. Regarding p504 expression, $80-100 \%$ sensitivity has been reported for this marker in diagnosis of prostate cancers (74-79).

\section{Bladder:}

In our study, 57.2\% showed CK7+/CK20+, 28.5\% CK7+/CK20-, and 14.3\% CK7-/CK20 + pattern, respectively.

GATA3 and high molecular weight keratin (HMWK) were positive in $50 \%$ and P63 expressed in $80 \%$ of cases.

Previous studies showed GATA3 expression is seen in 70-90\% of urothelial carcinomas (80-83). Overall, HMWK is positive in $65-97 \%$ of urothelial tumor cases $(84,85,86,87)$, In Kunju et al. p63 was positive in $92 \%$ of urothelial carcinomas (85). Thus using a panel consisting of P63, HMWK, and GATA3 will have a high sensitivity for detection of bladder origin.

\section{Pancreatobiliary system:}

In pancreatobiliary origin tumors $65.4 \%$ were CK7+/CK20- and $34.6 \%$ were CK7+/CK20+. CK19 was positive in all patients and GATA3 was positive in $12.5 \%$.

As in our study, Hornick et al. showed that CK19 is expressed in $100 \%$ of metastatic pancreatic adenocarcinomas to the liver (88) that is coordinate with a study by Zapata et al., which shows a sensitivity of $100 \%$ for CK19 marker in pancreatic adenocarcinoma (89). 
In a study by Miettinen et al., pancreatic ductal carcinoma was one of the most GATA3 positive non-mammary cancers with $37 \%$ sensitivity ( 90 ) and Clark et al. showed GATA3 positivity in $10 \%$ of pancreatic cancers (36). Although no specific marker is available for detection of pancreaticobiliary cancer, using CK19 may be helpful for the diagnosis of pancreaticobiliary origin cases.

In our study, immunohistochemical diagnosis and final diagnosis agreement in CUP cases was $59 \%$. In a study by Deyoung et al., IHC and final diagnosis concordance was seen in $67 \%$ of cases (91). Also, previous studies by Gambel et al., Brown et al., Dennis et al., and Park et al. showed that IHC predicted the primary origin of metastatic tumors in $64 \%, 66 \%, 67 \%$, and $65 \%$ of cases, respectively, that are approximately in the same range (92, $12,93,94)$. Also, in another previous study by Weiss et al., in $69 \%$ of cases, the origin site was diagnosed by an IHC study (5). The lower successful rate of finding primary origin of carcinomas in our study compared to other studies may be caused by incomplete clinical studies and imaging before patients death. Also, new IHC markers are updating and emerging day by day and there is not any definite standard IHC panel for determination of each carcinoma origin. In our study a uniform and homogenous panels were not used for each individuals and this limitation affects the precise sensitivity of each marker.

Another issue is that the expression of cytoplasmic IHC markers are usually dependent on the grade of tumor differentiation. In metastatic tumors, in many cases, the loss of tumor cell differentiation will occur and many tissue-specific cytoplasmic markers will be lost, but nuclear markers have the least changes. In this study by using IHC panels upper and lower GI, breast, kidney, prostate, ovary, lung and thyroid origin carcinoma was more readily diagnosed compared to Cervix and pancreatobiliary and liver origin tumors

\section{Conclusion:}

IHC study may aid in the diagnosis of CUP. However, some cases will still remain unknown origin after IHC study, so more diagnostic methods or gene expression studies may be needed for definite diagnosis.

\section{Declarations:}

- Ethics approval and consent to participate: Ethics committee of Shiraz University of Medical Sciences approved the study

- Consent for publication: The authors give their consent for publication

- Availability of data and materials: All the data are available.

- Competing interests: The author declare no competing interest.

- Funding: None

\section{References:}

1. Kandalaft PL, Gown AM. Practical Applications in Immunohistochemistry: Carcinomas of Unknown Primary Site. Arch Pathol Lab Med, 2016;140(6):50823.

2. Pavlidis N, Pentheroudakis G. Cancer of unknown primary site. Lancet, 2012, 14;379(9824):1428-35.

3. Massard C, Loriot Y, Fizazi K. Carcinomas of an unknown primary origin-diagnosis and treatment. Nat Rev Clin Oncol, 2011;8(12):701-10.

4. Zaun G, Schuler M, Herrmann K, Tannapfel A. CUP Syndrome-Metastatic Malignancy with Unknown Primary Tumor. Dtsch Arztebl Int, 2018;115(10):15762.

5. Weiss LM, Chu P, Schroeder BE, Singh V, Zhang Y, Erlander MG, et al. Blinded Comparator Study of Immunohistochemical Analysis versus a 92-Gene Cancer Classifier in the Diagnosis of the Primary Site in Metastatic Tumors. J Mol Diagn, 2013;15(2):263-9.

6. Hainsworth JD, Greco FA. Gene expression profiling in patients with carcinoma of unknown primary site: from translational research to standard of care. Virchows Archiv, 2014;464(4):393-402.

7. Oien KA, Dennis JL. Diagnostic work-up of carcinoma of unknown primary: from immunohistochemistry to molecular profiling. Ann Oncol, 2012 ;23 Suppl $10: \times 271-7$.

8. Gevaert O, Daemen A, De Moor B, Libbrecht L. A taxonomy of epithelial human cancer and their metastases. BMC Med Genomics; 2009;2:69.

9. Selves J, Long-Mira E, Mathieu MC, Rochaix P, Ilié M. Immunohistochemistry for Diagnosis of Metastatic Carcinomas of Unknown Primary Site. Cancers, 2018;10(4):108.

10. Krasinskas AM, Goldsmith JD. Immunohistology of the gastrointestinal tract. In: Dabbs DJ, editor. Diagnostic immunohistochemistry: theranostic and genomic applications. 4th ed. Philadelphia: Elsevier/Saunders; 2014. p.508-39.

11. Suriyonplengsaeng C. Concise immunohistochemistry in carcinoma of unknown primary origin. Chula Med J, $2018 ; 62$ (3): 575 - 92.

12. Brown RW, Campagna LB, Dunn JK, Cagle PT. Immunohistochemical Identification of Tumor Markers in Metastatic Adenocarcinoma :A Diagnostic Adjunct in the Determination of Primary Site. Am J Clin Pathol, 1997;107(1):12-9.

13. Magnusson K, de Wit M, Brennan DJ, Johnson LB, McGee SF, Lundberg E, et al. SATB2 in Combination With Cytokeratin 20 Identifies Over $95 \%$ of all Colorectal Carcinomas. Am J Surg Pathol, 2011 ;35(7):937-48.

14. Li Z, Rock JB, Roth R, Lehman A, Marsh WL, Suarez A, et al. Dual Stain With SATB2 and CK20/Villin Is Useful to Distinguish Colorectal Carcinomas From Other Tumors. Am J Clin Pathol, 2018;149(3):241-6.

15. Park SY, Kim BH, Kim JH, Lee S, Kang GH. Panels of Immunohistochemical Markers Help Determine Primary Sites of Metastatic Adenocarcinoma. Arch Pathol Lab Med. 2007;131(10):1561-7. 
16. Dragomir A, de Wit M, Johansson C, Uhlen M, Pontén F. The Role of SATB2 as a Diagnostic Marker for Tumors of Colorectal Origin. Am J Clin Pathol, 2014;141(5):630-8.

17. Su MC, Yuan RH, Lin CY, Jeng YM. Cadherin-17 is a useful diagnostic marker for adenocarcinomas of the digestive system. Modern Pathology, 2008;21(11):1379-86.

18. Bayrak R, Haltas H, Yenidunya S. The value of CDX2 and cytokeratins 7 and 20 expression in differentiating colorectal adenocarcinomas from extraintestinal gastrointestinal adenocarcinomas: cytokeratin 7-/20+ phenotype is more specific than CDX2 antibody. Diagnostic Pathology, 2012 ;7:9.

19. Ma C, Lowenthal BM, Pai RK. SATB2 is Superior to CDX2 in Distinguishing Signet Ring Cell Carcinoma of the Upper Gastrointestinal Tract and Lower Gastrointestinal Tract. Am J Surg Pathol, 2018;42(12):1715-22.

20. Al-Maghrabi J, Gomaa W, Buhmeida A, Al-Qahtani M, Al-Ahwal M. Loss of Villin Immunoexpression in Colorectal Carcinoma Is Associated with Poor Differentiation and Survival. ISRN Gastroenterology, 2013, 1-7.

21. Werling RW, Yaziji H, Bacchi CE, Gown AM. CDX2, a Highly Sensitive and Specific Marker of Adenocarcinomas of Intestinal Origin. Am J Surg Pathol. 2003;27(3):303-10.

22. Dei Tos AP. The reappraisal of gastrointestinal stromal tumors: from Stout to the KIT revolution. Virchows Arch. 2003;442(5):421-8.

23. Wang HL, Kim CJ, Koo J, Zhou W, Choi EK, Arcega R., et al. Practical Immunohistochemistry in Neoplastic Pathology of the Gastrointestinal Tract, Liver, Biliary Tract, and Pancreas. Arch Pathol Lab Med. 2017;141(9):1155-80.

24. Wong HH, Chu P. Immunohistochemical features of the gastrointestinal tract tumors. J Gastrointest Oncol. 2012;3(3):262-84.

25. Vang R, Gown AM, Wu LSF, Barry TS, Wheeler DT, Yemelyanova A, et al. Immunohistochemical expression of CDX2 in primary ovarian mucinous tumors and metastatic mucinous carcinomas involving the ovary: comparison with CK20 and correlation with coordinate expression of CK7. Mod Pathol. 2006;19(11):1421-8.

26. Lin F, Shi J, Zhu S, Chen Z, Li A, Chen T, et al. Cadherin-17 and SATB2 Are Sensitive and Specific Immunomarkers for Medullary Carcinoma of the Large Intestine. Arch Pathol Lab Med, 2014;138(8):1015-26.

27. Yan BC, Gong C, Song J, Krausz T, Tretiakova M, Hyjek E, et al. Arginase-1: a new immunohistochemical marker of hepatocytes and hepatocellular neoplasms. Am J Surg Pathol. 2010;34(8):1147-54.

28. Radwan NA, Ahmed NS. The diagnostic value of arginase-1 immunostaining in differentiating hepatocellular carcinoma from metastatic carcinoma and cholangiocarcinoma as compared to HepPar-1. Diagnostic Pathology, 2012;7:149.

29. Koehne de Gonzalez AK, Salomao MA, Lagana SM. Current concepts in the immunohistochemical evaluation of liver tumors. World J Hepatol 2015; 7(10): 1403-11.

30. O'Connell FP, Wang HH, Odze RD. Utility of immunohistochemistry in distinguishing primary adenocarcinomas from metastatic breast carcinomas in the gastrointestinal tract. Arch Pathol Lab Med. 2005;129(3):338-47.

31. Gomez-Fernandez C, Daneshbod Y, Nassiri M, Milikowski C, Alvarez C, Nadji M. Immunohistochemically Determined Estrogen Receptor Phenotype Remains Stable in Recurrent and Metastatic Breast Cancer. Am J Clin Pathol, 2008;130(6):879-82.

32. Sangoi AR, Shrestha B, Yang G, Mego O, Beck AH. The Novel Marker GATA3 is Significantly More Sensitive Than Traditional Markers Mammaglobin and GCDFP15 for Identifying Breast Cancer in Surgical and Cytology Specimens of Metastatic and Matched Primary Tumors. Appl Immunohistochem Mol Morphol. 2016; 24(4): 229-37.

33. Bhargava R, Beriwal S, Dabbs D. Mammaglobin vs GCDFP-15: An Immunohistologic Validation Survey for Sensitivity and Specificity. Am J Clin Pathol, 2007;127(1):103-13.

34. Yeh IT, Mies C. Application of Immunohistochemistry to Breast Lesions. Arch Pathol Lab Med.2008; 132: 349-58.

35. Wick MR, Lillemoe TJ, Copland GT, Swanson PE, Manivel JC, Kiang DT. Gross cystic disease fluid protein-15 as a marker for breast cancer: Immunohistochemical analysis of 690 human neoplasms and comparison with alpha-lactalbumin. Human Pathology, 1989;20(3):281-7.

36. Clark BZ, Beriwal S, Dabbs DJ, Bhargava R. Semiquantitative GATA-3 Immunoreactivity in Breast, Bladder, Gynecologic Tract, and Other Cytokeratin 7Positive Carcinomas. Am J Clin Pathol, 2014;142(1):64-71.

37. Tacha D, Zhou D, Cheng L. Expression of PAX8 in Normal and Neoplastic Tissues. Appl Immunohistochem Mol Morphol. 2011;19(4):293-9.

38. Ozcan A, Shen SS, Hamilton C, Anjana K, Coffey D, Krishnan B, Truong LD. PAX 8 expression in non-neoplastic tissues, primary tumors and metastatic tumors: a comprehensive immunohistochemical study. Mod Pathol, 2011;24(6):751-64.

39. Barr ML, Jilaveanu LB, Camp RL, Adeniran AJ, Kluger HM, Shuch B. PAX-8 expression in renal tumours and distant sites: A useful marker of primary and metastatic renal cell carcinoma? J Clin Pathol, 2015; 68(1), 12-7.

40. Tong GX, Yu WM, Beaubier NT, Weeden EM, Hamele-Bena D, Mansukhani MM, et al. Expression of PAX8 in normal and neoplastic renal tissues: an immunohistochemical study. Mod Pathol. 2009 ;22(9):1218-27.

41. Liu L, Qian J, Singh H, Meiers I, Zhou X, Bostwick DG. Immunohistochemical Analysis of Chromophobe Renal Cell Carcinoma, Renal Oncocytoma, and Clear Cell Carcinoma An Optimal and Practical Panel for Differential Diagnosis. Arch Pathol Lab Med. 2007 ;131(8):1290-7.

42. Sharma SG, Gokden M, McKenney JK, Phan DC, Cox RM, Kelly T, et al. The Utility of Pax-2 and Renal Cell Carcinoma Marker Immunohistochemistry in Distinguishing Papillary Renal Cell Carcinoma From Nonrenal Cell Neoplasms With Papillary Features. Appl Immunohistochem Mol Morphol, 2010 ;18(6):494-8.

43. Kaufmann O, Fietze E, Mengs J, Dietel M. Value of p63 and Cytokeratin 5/6 as Immunohistochemical Markers for the Differential Diagnosis of Poorly Differentiated and Undifferentiated Carcinomas. Am J Clin Pathol, 2001;116(6):823-30. 
44. Ma Y, Fan M, Dai L, Kang X, Liu Y, Sun Y, et al. Expression of p63 and CK5/6 in early-stage lung squamous cell carcinoma is not only an early diagnostic indicator but also correlates with a good prognosis. Thorac Cancer, 2015;6(3):288-95.

45. Warth A, Muley T, Herpel E, Meister M, Herth FJ, Schirmacher P, et al. Large-scale comparative analyses of immunomarkers for diagnostic subtyping of non-small-cell lung cancer biopsies. Histopathology, 2012;61(6):1017-25.

46. Vosmik M, Laco J, Sirak I, Beranek M, Hovorkova E, Vosmikova H, et al. Prognostic Significance of Human Papillomavirus (HPV) Status and Expression of Selected Markers (HER2/neu, EGFR, VEGF, CD34, p63, p53 and Ki67/MIB-1) on Outcome After (Chemo-) Radiotherapy in Patients with Squamous Cell Carcinoma of Uterine Cervix. Pathol Oncol Res, $2014 ; 20(1): 131-7$.

47. Reis-Filho JS, Simpson PT, Martins A, Preto A, Gartner F, Schmitt FC.Distribution of p63, cytokeratins $5 / 6$ and cytokeratin 14 in 51 normal and 400 neoplastic human tissue samples using TARP-4 multi-tumor tissue microarray. Virchows Arch, $2003 ; 443(2): 122-32$.

48. Li H, Jing X, Yu J, Liu J, Zhang T, Chen S, et al. A combination of cytokeratin 5/6, p63, p40 and MUC5AC are useful for distinguishing squamous cell carcinoma from adenocarcinoma of the cervix. Diagn Pathol, 2020;15(1):104.

49. Wang CW, Wu TI, Yu CT, Wu YC, Teng YH, Chin SY, et al. Usefulness of p16 for Differentiating Primary Pulmonary Squamous Cell Carcinoma From Cervical Squamous Cell Carcinoma Metastatic to the Lung. Am J Clin Pathol. 2009;131(5):715-22.

50. Ordo'nez NG. Value of estrogen and progesterone receptor immunostaining in distinguishing between peritoneal mesotheliomas and serous carcinomas. Hum Pathol. 2005;36(11):1163-7.

51. Yemelyanova A, Gown AM, Wu LSF, Holmes BJ, Ronnett BM, Vang R. PAX8 Expression in Uterine Adenocarcinomas and Mesonephric Proliferations. Int J Gynecol Pathol. $2014 ; 33(5): 492-9$.

52. Alkushi A, Irving J, Hsu F, Dupuis B, Liu CL, Rijn M, et al. Immunoprofile of cervical and endometrial adenocarcinomas using a tissue microarray. Virchows Arch, 2003;442:271-7.

53. Kounelis S, Kapranos N, Kouri E, Coppola D, Papadaki H, Jones MW. Immunohistochemical Profile of Endometrial Adenocarcinoma: A Study of 61 Cases and Review of the Literature. Mod Pathol, 2000;13(4):379-88.

54. Goldstein NS, Thomas M. Mucinous and Nonmucinous Bronchioloalveolar Adenocarcinomas Have Distinct Staining Patterns With Thyroid Transcription Factor and Cytokeratin 20 Antibodies. Am J Clin Pathol. 2001;116(3):319-25.

55. Zamecnik J, Kodet R. Value of thyroid transcription factor-1 and surfactant apoprotein A in the differential diagnosis of pulmonary carcinomas: a study of 109 cases. Virchows Arch, 2002;440(4):353-61.

56. Jerome Marson V, Mazieres J, Groussard O, Garcia O, Berjaud J, Dahan M, et al. Expression of TTF-1 and cytokeratins in primary and secondary epithelial lung tumours: correlation with histological type and grade. Histopathology, 2004;45(2):125-34.

57. Jagirdar J. Application of Immunohistochemistry to the Diagnosis of Primary and Metastatic Carcinoma to the Lung. Arch Pathol Lab Med. 2008;132(3):384-96.

58. Lau SK, Luthringer DJ, Eisen RN. Thyroid transcription factor-1: a review. Appl Immunohistochem Mol Morphol. 2002;10(2):97-102.

59. Ye J, Hameed O, Findeis-Hosey J, Fan L, Li F, McMahon L, et al. Diagnostic utility of PAX8, TTF-1 and napsin A for discriminating metastatic carcinoma from primary adenocarcinoma of the lung. Biotech Histochem. 2012;87(1):30-4.

60. Leech SN, Kolar AJ, Barrett PD, Sinclair SA, Leonard N. Merkel cell carcinoma can be distinguished from metastatic small cell carcinoma using antibodies to cytokeratin 20 and thyroid transcription factor 1. J Clin Pathol. 2001;54(9):727-9.

61. Shield PW, Crouch SJ, Papadimos DJ, Walsh MD. Identification of metastatic papillary thyroid carcinoma in FNA specimens using thyroid peroxidase immunohistochemistry. Cytopathology, 2018;29(3):227-32.

62. Bejarano PA, Nikiforov YE, Swenson ES, Biddinger PW. Thyroid transcription factor-1, thyroglobulin, cytokeratin 7, and cytokeratin 20 in thyroid neoplasms. Appl Immunohistochem Mol Morphol. 2000;8(3):189-94.

63. Liu H, Lin F. Application of Immunohistochemistry in Thyroid Pathology. Arch Pathol Lab Med, 2015 ;139(1):67-82.

64. Fabbro D, Di Loreto C, Beltrami CA, Belfiore A, Di Lauro R, Damante G. Expression of thyroid-specific transcription factors TTF-1 and PAX-8 in human thyroid neoplasms. Cancer Res. 1994;54(17):4744-9.

65. Cimino-Mathews A, Sharma R, Netto GJ. Diagnostic Use of PAX8, CAIX, TTF-1, and TGB in Metastatic Renal Cell Carcinoma of the Thyroid. Am J Surg Pathol, 2011;35(5):757-61.

66. Nonaka D, Tang Y, Chiriboga L, Rivera M, Ghossein R. Diagnostic utility of thyroid transcription factors Pax8 and TTF-2 (FoxE1) in thyroid epithelial neoplasms. Mod Pathol. 2008;21(2):192-200.

67. Zhang P, Zuo H, Nakamura Y, Nakamura M, Wakasa T, Kakudo K. Immunohistochemical analysis of thyroid-specific transcription factors in thyroid tumors. Pathol Int. 2006;56(5):240-5.

68. Liu H, Lin F, DeLellis RA. Thyroid and parathyroid gland. In: Lin F, Prichard JW, Liu H, Wilkerson M, Scheurch C, eds. Handbook of Practical Immunohistochemistry: Frequently Asked Questions. New York, NY: Springer; 2011:137-58.

69. Svanholm H. Evaluation of commercial immunoperoxidase kits for prostatic specific antigen and prostatic specific acid phosphatase. Acta Pathol Microbiol Immunol Scand A. 1986;94(1):7-12.

70. Liu H, Shi J, Wilkerson M, Yang XJ, Lin F. Immunohistochemical evaluation of ERG expression in various benign and malignant tissues. Ann Clin Lab Sci. 2013;43(1):3-9.

71. Bernacki KD, Fields KL, Roh MH. The utility of PSMA and PSA immunohistochemistry in the cytologic diagnosis of metastatic prostate carcinoma. Diagn Cytopathol, 2014;42(7):570-5. 
72. Mai KT, Roustan Delatour NLD, Assiri A, Al-Maghrabi H. Secondary prostatic adenocarcinoma: A cytopathological study of 50 cases. Diagn Cytopathol, $2007 ; 35(2): 91-5$.

73. Renshaw AA, Nappi D, Cibas ES. Cytology of metastatic adenocarcinoma of the prostate in pleural effusions. Diagn Cytopathol.1996;15(2):103-7.

74. Varma M, Jasani B. Diagnostic utility of immunohistochemistry in morphologically difficult prostate cancer: review of current literature. Histopathology, $2005 ; 47(1), 1-16$.

75. Jiang Z, Wu CL, Woda BA, Iczkowski KA, Chu PG, Tretiakova MS, et al. Alpha-methylacyl-CoA racemase: a multi-institutional study of a new prostate cancer marker. Histopathology, 2004; 45(3), 218-25.

76. Molinié V, Fromont G, Sibony M, Vieillefond A, Vassiliu V, Cochand-Priollet B, et al. Diagnostic utility of a p63 / alphamethyl-CoA-racemase (p504s) cocktail in atypical foci in the prostate. Mod Pathol. 2004;17(10):1180-90.

77. Magi Galluzzi C, Luo J, Isaacs WB, Hicks JI, de Marzo AM, Epstein JI. Alphamethyl-CoA Racemase: a variably sensitive immunohistochemical marker fro the diagnosis of small prostatic cancer foci on needle biopsy. Am J Surg Pathol. 2003;27(8):1128-33.

78. Kumaresan K, Kakkar N, Verma A, Mandal A, Singh S, Joshi K. Diagnostic utility of a-methylacyl CoA racemase (P504S) \& HMWCK in morphologically difficult prostate cancer. Diagn Pathol, 2010;5:83.

79. Beach R, Gown AM, de Peralta-Venturina MN, Folpe AL, Yaziji H, Salles PG, et al. P504S Immunohistochemical Detection in 405 Prostatic Specimens Including 376 18-Gauge Needle Biopsies. Am J Surg Pathol, 2002;26(12):1588-96.

80. Mohammed KH, Siddiqui MT, Cohen C. GATA3 immunohistochemical expression in invasive urothelial carcinoma. Urologic Oncology: Seminars and Original Investigations, $2016 ; 34(10): 432$.

81. Wang L, Greaves W, Sabo E, Noble L, Tavares R, Ng T, et al. GCDFP-15 positive and TTF-1 negative primary lung neoplasms: a tissue microarray study of 381 primary lung tumors. Appl Immunohistochem Mol Morphol. 2009;17(6):505-11.

82. Watson MA, Fleming TP. Mammaglobin, a mammary-specific member of the uteroglobin gene family, is overexpressed in human breast cancer. Cancer Res. 1996;56(4):860-5.

83. Clark BZ, Beriwal S, Dabbs DJ, Bhargava R. Semiquantitative GATA-3 Immunoreactivity in Breast, Bladder, Gynecologic Tract, and Other Cytokeratin 7Positive Carcinomas. Am J Clin Pathol, $2014 ; 142(1): 6471$

84. Chuang AY, DeMarzo AM, Veltri RW, Sharma RB, Bieberich CJ, Epstein JI. Immunohistochemical Differentiation of High-grade Prostate Carcinoma From Urothelial Carcinoma. Am J Surg Pathol, 2007;31(8):1246-55.

85. Kunju LP, Mehra R, Snyder M, Shah RB. Prostate specific antigen, high-molecular-weight cytokeratin (clone 34ßE12), and/or p63: an optimal immunohistochemical panel to distinguish poorly differentiated prostate adenocarcinoma from urothelial carcinoma. Am J Clin Pathol. 2006;125:675-81.

86. Genega EM, Hutchinson B, Reuter VE, Gaudin PB. Immunophenotype of High-Grade Prostatic Adenocarcinoma and Urothelial Carcinoma. Modern Pathology, 2000;13(11):1186-91.

87. Skinnider BF, Folpe AL, Hennigar RA, Lim SD, Cohen C, Tamboli P, et al. Distribution of Cytokeratins and Vimentin in Adult Renal Neoplasms and Normal Renal Tissue. Am J Surg Pathol, 2005;29(6):747-54.

88. Hornick JL, Lauwers GY, Odze RD. Immunohistochemistry Can Help Distinguish Metastatic Pancreatic Adenocarcinomas From Bile Duct Adenomas and Hamartomas of the Liver. Am J Surg Pathol.2005;29(3):381-9.

89. Zapata M, Cohen C, Siddiqui MT. Immunohistochemical expression of SMAD4, CK19, and CA19-9 in fine needle aspiration samples of pancreatic adenocarcinoma: Utility and potential role. CytoJournal, 2007;4:13.

90. Miettinen M, Mccue PA, Sarlomo-Rikala M, Rys J, Czapiewski P, Wazny K, et al. GATA 3 - a multispecific but potentially useful marker in surgical pathology - a systematic analysis of 2500 epithelial and non-epithelial tumors. Am J Surg Pathol. 2014 ; 38(1): 13-22.

91. DeYoung BR, Wick MR. Immunohistologic evaluation of metastatic carcinomas of unknown origin: an algorithmic approach. Semin Diagn Pathol. 2000;17:184-93.

92. Gamble AR, Bell JA, Ronan JE, Pearson D, Ellis IO. Use of tumour marker immunoreactivity to identify primary site of metastatic cancer. 1993;306(6873):295-8.

93. Dennis JL, Hvidsten TR, Wit EC, Komorowski J, Bell AK, Downie I, et al. Markers of Adenocarcinoma Characteristic of the Site of Origin: Development of a Diagnostic Algorithm. Clin Cancer Res, 2005;11(10):3766-72.

94. Park SY, Kim BH, Kim JH, Lee S, Kang GH. Panels of immunohistochemical markers help determine primary sites of metastatic adenocarcinoma. Arch Pathol Lab Med. 2007;131(10):1561-7.

\section{Figures}




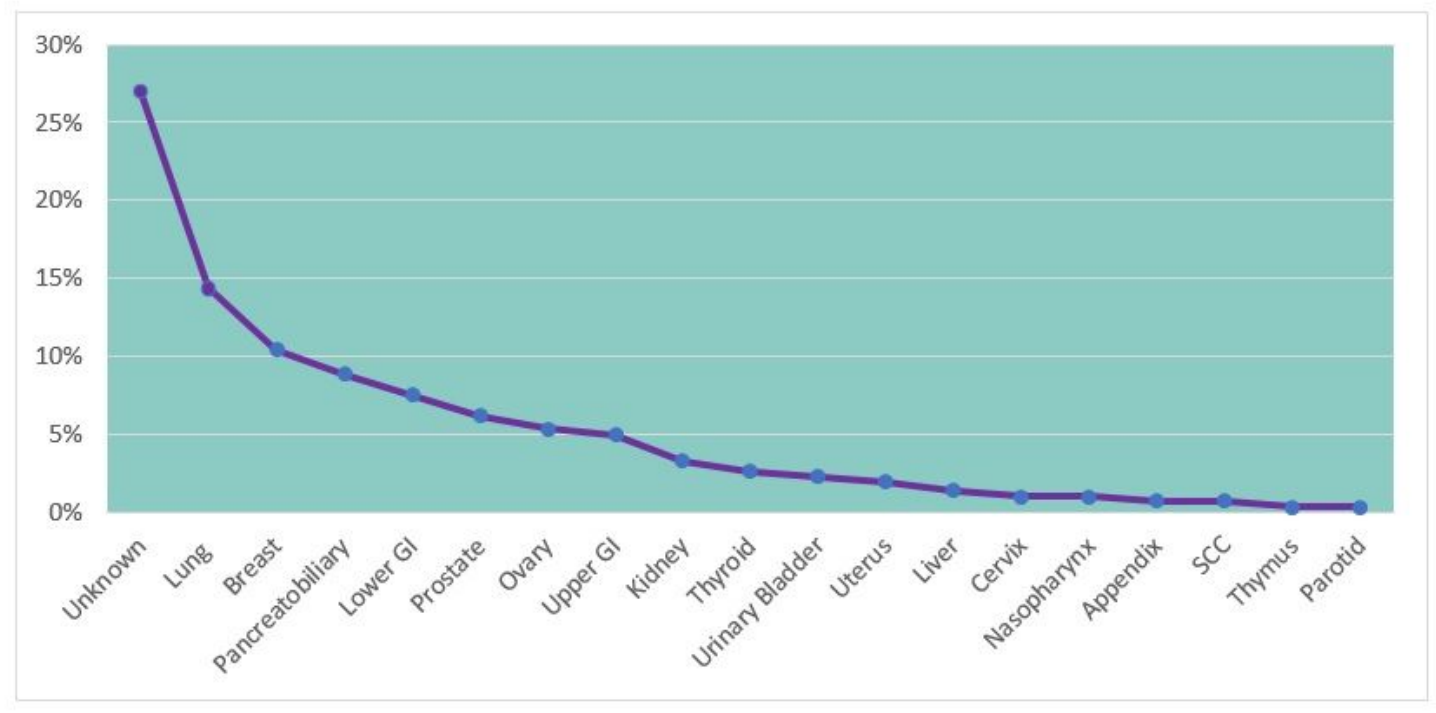

Figure 1

The frequency of original organs of metastatic cases

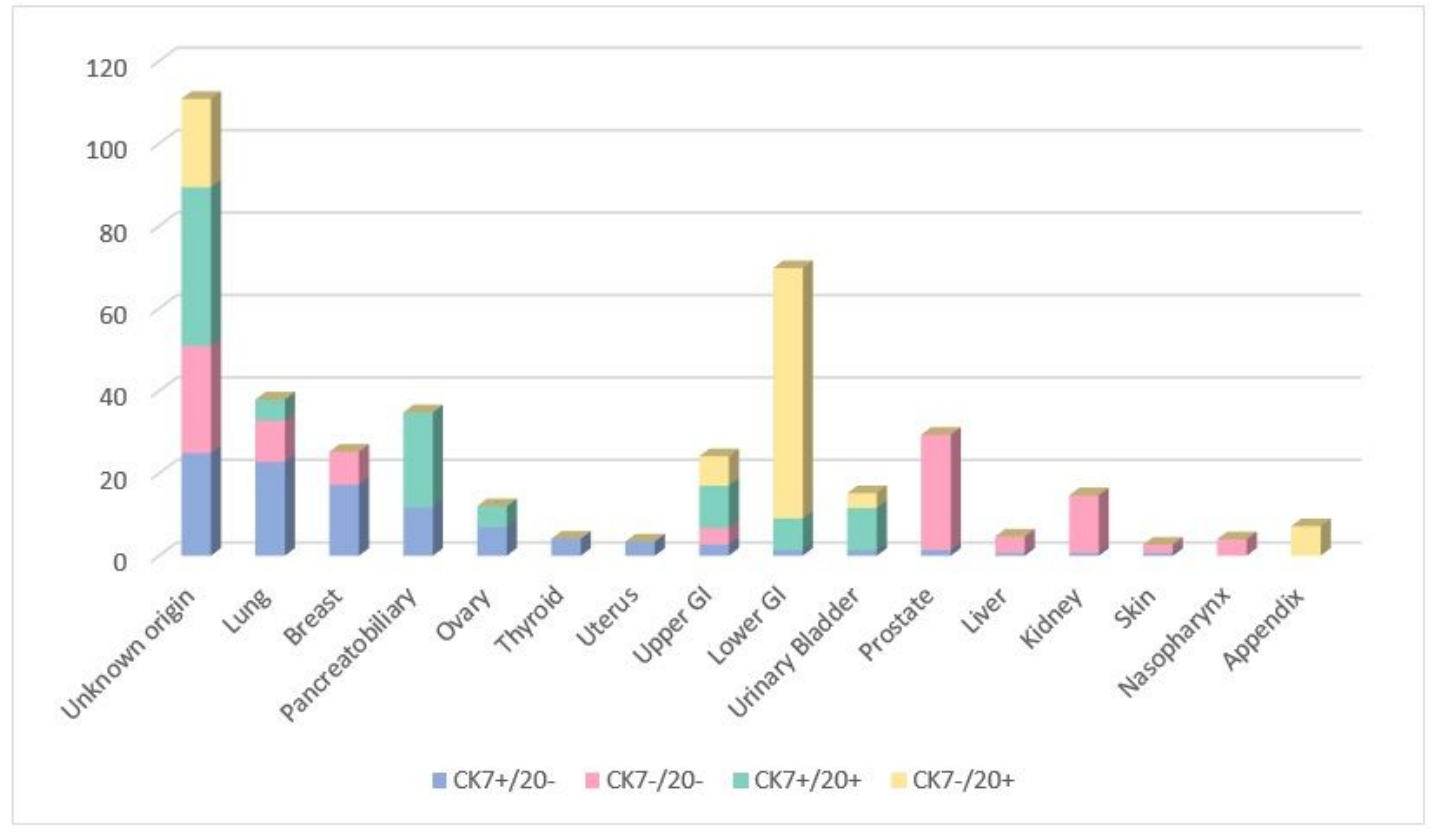

Figure 2

Different patterns of CK7/CK20 expression in various clinical diagnoses of CUPs 